\title{
CARDIAC CATHETERIZATION IN DOGS
}

\author{
William H. Noble, B.A., M.D., DiP.ANaEs, F.R.C.P.(C) \\ AND J. Colin KaY, A.I.M.L.T. (ENG.)
}

\begin{abstract}
INTRODUCTION
MANY INVESTIGATORS require cardiac catheterization data as a part of the analysis of experimental effects on the cardiopulmonary systems. We have gained a great deal of experience in both left and right heart catheterization in dogs. Initially our experience was frustrated by lack of information. This paper outlines our methods for cardiac catheterization in dogs which have been successful in 198 consecutive animals almost without exception. The techniques described require a minimum of surgery, no thoracotomy, no radiography, and are inexpensive.
\end{abstract}

\section{Methods and Materials}

Right heart catheterization: The Swan Ganz catheter ${ }^{1}$ has utilized the principle of a floating catheter to follow the flow of blood into the right heart and through into the pulmonary artery. We used the same principle by constructing a catheter of flexible, inexpensive, medical grade silastic (0.062 in. I.D., 0.095 in. O.D., length $60 \mathrm{~cm}$ ). This material is inert and nonreactive with tissues. The catheter has side holes cut in 1-2 cm from the tip to improve sampling of blood.

The $\operatorname{dog}$ is anaesthetized and placed prone on the table. The right external jugular vein is easily dissected out. The catheter is passed down the venous system until the pressures recorded from it are right ventricular. On occasion the passage has been difficult but by moving the catheter in and out and raising the right forelimb or changing the dog's position, the time is almost never more than five minutes. The pulmonary artery has been reached when the diastolic pressure rises and a notch appears in the downstroke of the pressure tracing (Figure 1). Timing catheter advancement with inspiration once inside the ventricle seems to be of value. The side holes also help in positioning the catheter. Once pulmonary artery pressures are found the catheter is very slowly withdrawn until a tracing that is partly ventricle and partly pulmonary artery is obtained. Advancing the catheter until the diastolic pressure first rises ensures that the catheter is in the main pulmonary artery.

Left heart catheterization: Here the flow of blood opposes the passage of a catheter when approached from the systemic side. A stiff catheter is therefore required. We have used a commercially available catheter (CORDIS PIGTAIL $7 \mathrm{~F}$ catheter). The left carotid artery is exposed by making a midline neck incision to expose the trachea. By moving to the side of the trachea and posteriorly

Department of Anaesthesia, University of Toronto and St. Michael's Hospital, Toronto, Ontario. 


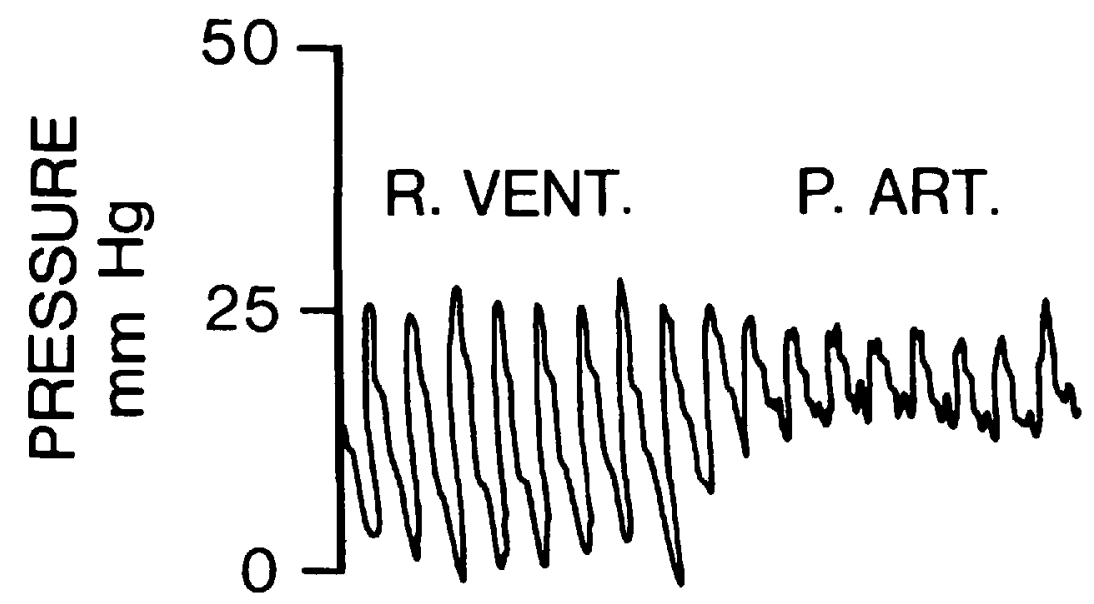

Figure 1. Right ventricular (R. Vent.) followed by pulmonary artery pressure (P. Art.) tracings as the silastic catheter enters the pulmonary artery. Diastolic pressure rose from 0 to $13 \mathrm{~mm} \mathrm{Hg}$ once the pulmonary artery was reached.

the internal carotid artery will be felt and is easily pulled out and dissected free of the vagus nerve. The catheter is passed down the internal carotid artery. The catheter usually goes directly into the left ventricle with the diastolic pressure dropping to low values (5-15 $\mathrm{mm} \mathrm{Hg}$ ) (Figure 2). If $20 \mathrm{~cm}$ of catheter has been passed and left ventricular pressure tracings do not appear the catheter has passed down the descending aorta. Removal of the catheter and reinsertion usually results in left ventricular pressures. Once in the left ventricle manipulation back and forth will result in the catheter passing into the left atrium with its lower pressure (Figure 2) and a and $v$ waves (Figure 3). Manoeuvres we have found useful include withdrawing the catheter slowly once in the left ventricle until aortic pressures are just seen, then quickly advancing the catheter. If this is not successful in reaching the left atrium after $20 \mathrm{~cm}$ is passed, withdrawal and twisting the catheter for the next insertion will often be successful.

\section{Results}

Right heart catheterization: In 198 dogs the pulmonary artery was successfully cannulated 197 times, for a 99.5 per cent success rate. Very infrequently the cannula would slip out of the pulmonary artery but always we have been able to replace it. This, in spite of frequent injections for indicator dilution studies and blood withdrawal for gas analysis. Usually the insertion takes five minutes.

The natural frequency of our catheter is 9 cycles/sec. This compares with a natural frequency of $14 \mathrm{cycles} / \mathrm{sec}$. in the Swan Ganz catheter. A comparison of tracings from a $7 F$ Swan Ganz catheter and our silastic catheter in the same dog is presented in Figure 4. The silastic catheter gives slight motion artifact but an adequate frequency response.

Left heart catheterization: In 46 dogs the left atrial catheter was successfully cannulated 46 times for a 100 per cent success rate. Ventricular arrhythmias occurred while passing this catheter but with the exception of one dog these have 


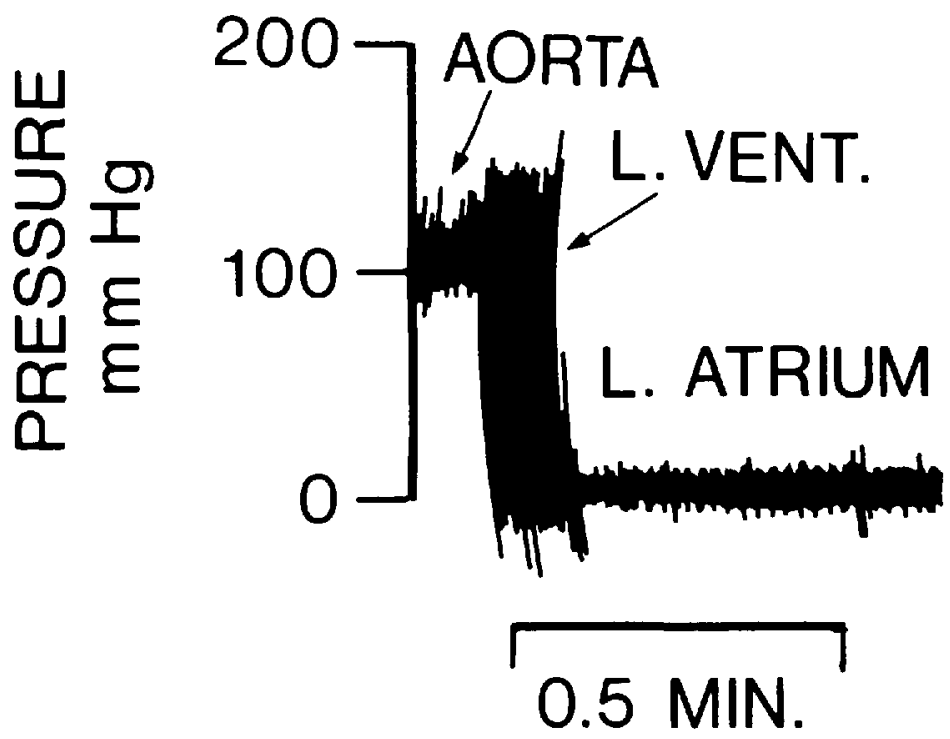

Ficure 2. Pressure tracings from the left atrial catheter as the tip passes from aorta to left ventricle (L. Vent.) to left atrium (L. Atrium). Passage time here was $25 \mathrm{sec}$.

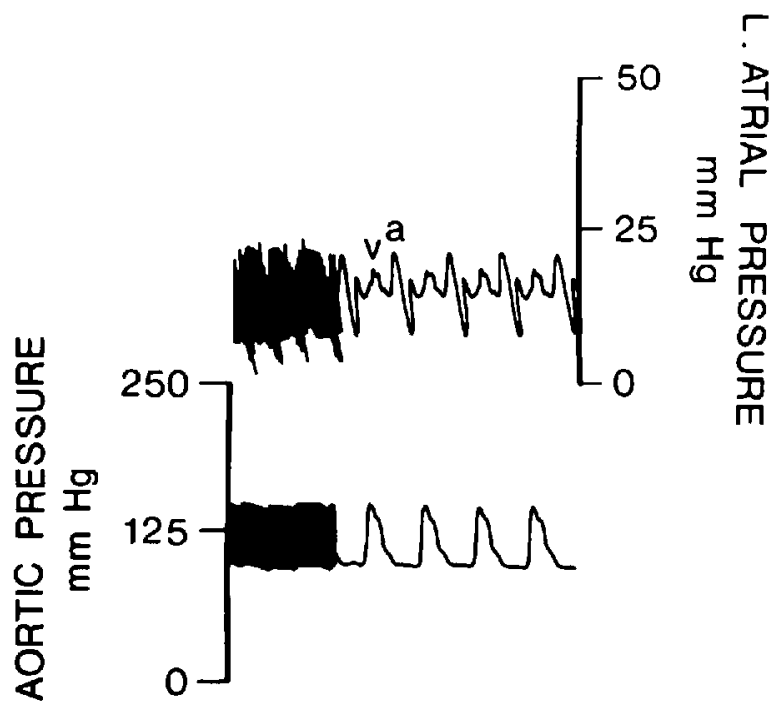

Figune 3. Simultaneous pressure tracings from the left atrium, indicating a and $\vee$ waves, and the aorta.

stopped without the use of drugs after the cannula was in place. Blood withdrawal has not been a problem nor has the cannula slipped out of the left atrium despite fluid infusions. Insertion times varied from $15 \mathrm{sec}$ to $45 \mathrm{~min}$ with an average of less than $10 \mathrm{~min}$. The natural frequency of this catheter is $15.5 \mathrm{cycles} / \mathrm{sec}$ and motion artifact was reduced by taping the catheter to the table (Figure 3 ). 


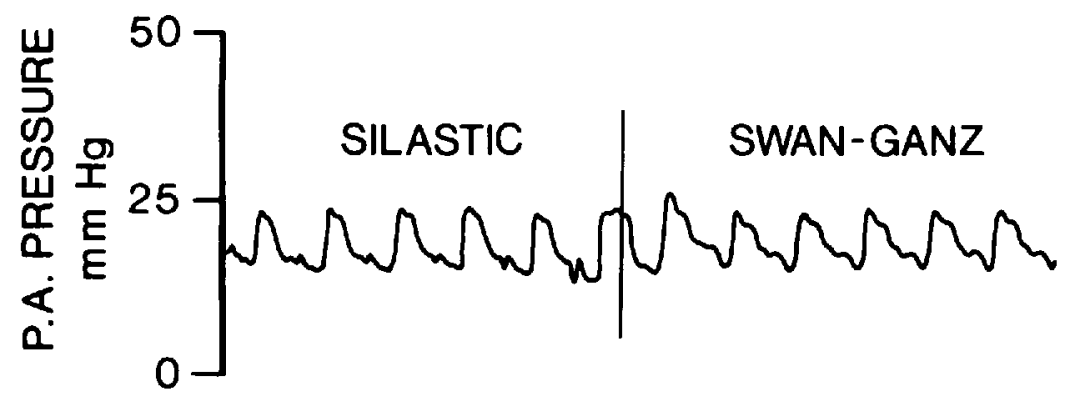

Figure 4. Pressure tracings in the same dog with both a silastic and Swan Ganz pulmonary artery catheter in place. At the line a stop cock was turned to switch from one catheter to the other. The same transducer and recording apparatus were used for both tracings, the only difference being the type of catheter.

\section{Discussion}

The Swan Ganz catheter is a useful tool in patient use, however we have had difficulties in dogs. To be positive of a wedge pressure we should be able to withdraw arterialized blood through the catheter. At times, blood could not be obtained in the wedge position. Blowing up the balloon usually does result in Swan Ganz catheter pressures falling but this may only mean that the flow of blood past the catheter has been reduced and therefore the pressure might not reflect left atrial pressures but some variable amount of pulmonary artery pressure. In order to be more certain of left atrial pressures we decided to use left atrial catheters.

There are several methods for left atrial catheterization most of which require radiographic help, transtracheal insertion or a thoracotomy. We have found the internal carotid artery approach simple and reliable. The collateral circulation to the dog's brain is so extensive that clamping one internal carotid does not alter cerebral blood flow.

\section{SumMary}

Techniques for right and left heart catheterization in dogs are described which have proven safe and reliable without altering the physiological state.

\section{RÉSUMÉ}

Nous avons décrit des techniques de cathétérisme cardiaque droit et gauche pratiquées chez le chien. Ces techniques se sont révélées inoffensives, fiables et ne provoquent pas de perturbations de l'état physiologique.

\section{ACKNOWLEDGMENTS}

We gratefully acknowledge the expert technical assistance of Mr. G. Carmichael and Mrs. Donna Joy Toelle.

Nembutal was supplied by Abbott. 
This work was supported by Medical Research Council of Canada, grant number MA 4263, and the Canadian Tuberculosis and Respiratory Disease Association, grant number 3-333-269-41.

\section{REFERENCE}

1. Swan, H.J.C., Ganz, W., Forrester, J., et al. Catheterization of the heart in man with the use of a flow-directed balloon-tipped catheter. N. Engl. J. Med. 283: 447-451 (1970). 